\title{
Educação e produção de moda na Segunda Guerra Mundial: \\ as voluntárias da Legião Brasileira de Assistência*
}

\author{
Ivana Guilherme Simili**
}

\begin{abstract}
Resumo
As transformações observadas na educação e na moda durante os anos de 1942-1945, da participação do Brasil na Segunda Guerra mundial, são analisadas por intermédio dos estilos e perfis criados pela Legião Brasileira de Assistência para as voluntárias. Examino os cursos, os serviços e as atividades criadas pela instituição a fim de envolver e preparar as voluntárias para revelar os estilos e perfis femininos que emergem no cenário nacional e mostrar como a guerra refletiu $e$ influenciou o comportamento $e$ o vestuário femininos.
\end{abstract}

Palavras-chave: Educação, Moda, Voluntárias, Legião Brasileira de Assistência, Segunda Guerra Mundial.

\footnotetext{
* Recebido para publicação em julho de 2007, aceito em fevereiro de 2008. Este artigo apresenta os resultados da pesquisa desenvolvida com o apoio financeiro do CNPq.

** Doutora em História, professora do Departamento de Fundamentos da Educação da Universidade Estadual de Maringá/UEM. ivanasimili@ig.com.br.
} 
Educação e produção de moda na segunda guerra mundial

Education and Fashion Production during the Second World War: the Volunteers of Brazilian Legion of Assistance

\begin{abstract}
The transformations observed in education and in fashion between 1942-1945, the years in which Brazil took part in Second World War, are analyzed through styles and profiles created by Brazilian Legion of Assistance for the volunteers. The courses, the services and the activities created by the institution with the aim of involving and preparing the volunteers will be analyzed so as to reveal the styles and female profiles that emerge from the national scenario and show how the war reflected and influenced female behavior and clothing.
\end{abstract}

Key Words: Education, Fashion, Volunteers, Brazilian Legion of Assistance, Second World War. 
Na historiografia da educação, o século XIX e o início do XX são caracterizados como um período em que os projetos educacionais visando à formação das mulheres orientaram-se pela concepção de que elas deviam ser preparadas para o lar, para o desempenho de funções entendidas pelos homens como apropriadas ao feminino, quais sejam: o cuidado do marido, dos filhos e o desenvolvimento de habilidades e competências que estavam relacionadas à posição que ocupavam na família e na sociedade, nas quais deveriam comportar-se de acordo com princípios específicos como a cooperação com o outro sexo, a obediência, o altruísmo, a docilidade entre outras.

No entanto, a história e a historiografia da educação ainda não dedicaram atenção às transformações que se processaram no modelo de feminilidade durante o período da participação brasileira na Segunda Guerra Mundial ocorrida entre 1942 e 1945. Refletir sobre os modos pelos quais os contextos políticohistóricos, como é o caso de um conflito mundial, introduzem mudanças na educação e no modelo de feminilidade - mediante a associação de novos conceitos aos papéis e desempenhos femininos, alterando as noções de família e de lar - torna-se imperioso para indicar as rupturas, mas também as permanências $e$ as continuidades.

Os estudos panorâmicos são a tônica dos trabalhos sobre a moda da Segunda Guerra Mundial, tanto na literatura brasileira como na estrangeira. Indicam-se as principais mudanças nas roupas, os principais nomes do estilismo, as tendências mais fortes observadas no período, ganhando destaque nas narrativas as influências exercidas pelos uniformes dos soldados na moda feminina, a sobriedade que o vestuário feminino adquire e os principais traços nos modos da produção do visual pelas mulheres. ${ }^{1}$

1 A produção sobre a moda na Guerra é vasta, porque uma tendência nas narrativas é conceber a história da moda por períodos, nos quais são apresentadas suas principais características. Nessa produção, sempre é reservado 
Educação e produção de moda na segunda guerra mundial

Contrastando com esse tipo de produção bibliográfica, situase o estudo de Dominique Veillon (2004) sobre a moda francesa na Segunda Guerra Mundial, entre 1939 e 1944, referente à ocupação alemã. Partindo do conceito de moda como "manifestação da vida sob todas as suas formas, maneiras de ser e de comportar", como um "observatório privilegiado do ambiente político, econômico e cultural de uma época", a autora embasa sua análise na história cultural para mostrar como a guerra, um fenômeno sócio-político, foi vivenciada pelos(as) franceses(as). Ela mostra, por exemplo, como as restrições econômicas e comerciais impostas pelos alemães, a reserva de estoque e as limitações de recursos para os fabricantes de roupas e de acessórios foram fatores criadores de moda, levando, por um lado, os estilistas a improvisarem, usando novos materiais na produção de roupas e acessórios e, por outro, as francesas a criar, quando o lema era inovar com o que se tinha ou usar a criatividade na invenção das peças e objetos. A moda criada mostra-se fértil: surgem chapéus feitos de jornal, blusas de seda de pára-quedas e solas de cortiça que, juntamente com a madeira e o metal, são adicionadas aos calçados para substituir o couro, material escasso na época. A tintura de iodo era empregada na perna como forma de substituir a meia-calça, etc.

Veillon aponta para um aspecto importante de que a guerra mudou o panorama da moda, tendo as francesas como uma das principais personagens. Elas tiveram que adotar práticas criativas, produtoras de novas maneiras de compor o visual e constituidoras de novas tendências e estilos de moda.

Neste texto, os pontos historiográficos que remetem à educação e à moda motivaram e inspiraram o exame da trajetória das voluntárias da Legião Brasileira de Assistência. Dessa forma, analiso os estilos e perfis que, com elas, emergiram no cenário nacional, a fim de verificar as transformações observadas na

um capítulo para o assunto. Das obras consultadas e que permitiram essa análise, cito algumas: Laver, 1989; Baudot, 2000; Braga, 2005; Moutinho, 2005. 
educação e na moda para as mulheres durante os anos da participação do Brasil na Guerra.

A Legião Brasileira de Assistência foi criada pela primeiradama Darcy Vargas logo após Getúlio Vargas declarar o ingresso do Brasil na Segunda Guerra Mundial. O objetivo fixado pela esposa de Vargas para a instituição foi o de "amparar os soldados e seus familiares". Para desenvolver o projeto assistencial, ela contou com o apoio do empresariado, do Governo $e$ principalmente das mulheres provenientes da elite e da classe média do Rio de Janeiro, população composta por jovens e senhoras. Somente na capital carioca, onde funcionava a sede da instituição, milhares de personagens femininas transformaram-se em voluntárias da Legião Brasileira de Assistência. Para elas, a instituição criou uma variedade de cursos preparatórios, por exemplo, os de formação de voluntárias da defesa passiva, de alimentação, para samaritanas socorristas, para visitadoras $e$ educadoras sociais, entre outros. Além dos cursos, em nome da assistência social de guerra, centenas de mulheres foram mobilizadas para os mais diversos serviços, como os de costura $e$ produção de bandagens, que serviram de roupas e materiais hospitalares e eram doados aos soldados mobilizados $e$ seus familiares para serem empregados no atendimento médicohospitalar no front de guerra. Associam-se a essas formas de arregimentação feminina as campanhas desenvolvidas que tinham como público-alvo as mulheres. Foram exemplares, nesse sentido, a campanha desencadeada para composição de quadros das "Madrinhas dos Combatentes", cuja finalidade era conseguir mulheres que se dispusessem a escrever cartas aos combatentes no front e mulheres que participassem de programas radiofônicos transmitindo mensagens de conforto para os soldados ou, ainda, a campanha da Horta da Vitória, cujo fito era fazer de cada mulher 
Educação e produção de moda na segunda guerra mundial

uma cultivadora de alimentos - hortaliças e leguminosas - nos quintais da casa. ${ }^{2}$

Neste texto, a interpretação dada para o percurso da Legião Brasileira de Assistência no período da participação do país no conflito mundial é a de que ela se constituiu em importante centro de educação e de moda. Abordar os cursos promovidos, os tipos de serviços criados, as atividades nas quais as mulheres se envolveram para mostrar as transformações operadas nos conceitos, nos comportamentos, nas atitudes e no vestuário que construíram as voluntárias, foi o encaminhamento dado para apontar as mudanças na educação e na moda.

Nessa abordagem, a Legião Brasileira de Assistência foi concebida como uma instância pedagógico-cultural que educava mulheres e produzia moda. Essa perspectiva situou a análise no universo dos estudos culturais, articulados aos da educação e da moda, porque parte do princípio da existência de várias instâncias pedagógico-culturais que participam e atuam, junto com a escola formal, na formação dos sujeitos, modelando-os na criação de suas concepções, seus valores acerca do mundo e de si mesmos, de suas identidades, dos papéis sociais a desempenhar, de suas maneiras de comportar-se, agir e, até mesmo, suas representações acerca de como se vestir e se apresentar. ${ }^{3}$

Busquei os processos pedagógicos desenvolvidos pela instituição na modelagem de mulheres em voluntárias nos documentos - escritos e imagéticos - da Legião Brasileira de Assistência, no noticiário da imprensa, nos Boletins e Relatórios, nos acervos do Centro de pesquisa e documentação da História da Fundação Getúlio Vargas - CPDOC - e nas fotografias, com vistas a identificar os estilos e perfis voluntários que foram processados pela instituição.

${ }^{2}$ A análise da Legião Brasileira de Assistência tem suporte no estudo de Simili (2008).

3 Existem vários estudos que vêm analisando a educação na perspectiva culturalista. Os trabalhos que serviram de base para a reflexão foram: Goellner, 2003; Felipe, 2004; Soares, 2004. 
O conceito de representação social foi nosso instrumental teórico-metodológico no exame da documentação. Conforme Denise Jodelet (2001:08), as representações sociais podem ser definidas como uma

forma de conhecimento socialmente elaborada $e$ compartilhada, que tem um objetivo prático e concorre para a construção de uma realidade comum a um conjunto social.

As representações sociais compõem-se de elementos informativos, ideológicos, normativos, crenças, valores, atitudes, opiniões, imagens etc., que são organizados sempre sob a aparência de um saber que diz algo sobre o estado da realidade.

Localizei as concepções, os valores, as atitudes, os comportamentos e maneiras de se compor o visual que produziram estilos $e$ perfis femininos nas representações elaboradas pela Legião Brasileira de Assistência para transformar mulheres em voluntárias.

A hipótese que norteia a narrativa é a de que na documentação estão as representações que orientaram a educação das mulheres e a produção de moda. Desse modo, educação e moda são tratadas de forma articulada. O elemento de ligação entre ambas pode ser localizado num conceito-chave, o da mudança. A abertura que Gilda de Melo e Souza (1987:19) faz no estudo pioneiro sobre a moda no século XIX é esclarecedora na amarração e articulação entre os conceitos: "O conceito de moda como conseqüência de variações constantes". Ao conceber a moda como um fenômeno que não pode ser tratado como universal, mas sempre dependente da cultura e dos ideais de uma época, Gilda tinha como propósito acompanhar pelo vestuário as mudanças introduzidas pelo advento da burguesia $e$ do industrialismo no século XIX, mostrando a composição do estilo definido pelos modos de ser e de pensar que emergiram no período. 
Educação e produção de moda na segunda guerra mundial

"O estilo" - modo de ser e de pensar - que surgiu na guerra entre e com as voluntárias foi trazido à tona pela documentação. Esse é um aspecto que deve ser destacado: a compreensão do estilo das voluntárias articula-se ao contexto da época, momento no qual o patriotismo de guerra se fazia muito presente, fundamentando concepções tais como a de povo unido diante do inimigo comum, a da união de esforços e cooperação entre os sexos, que repercutiram de múltiplas maneiras na formação e na atuação delas. ${ }^{4}$

Associado a esse aspecto existe um outro: embora o estilo da época esteja registrado nas voluntárias; os cursos, as atividades e serviços foram modeladores de perfis femininos e voluntários, instalando diferenças no seu modo de ser, de se comportar e se vestir e no pertencimento delas aos grupos. Esse é um ponto que merece destaque, porque situa a análise da educação e da moda no universo de debates historiográficos acerca da história das mulheres e do gênero. $\mathrm{O}$ tom desse debate, desde o surgimento do conceito de gênero nos anos 70, tem sido marcado pelo intuito de ultrapassar os estudos meramente descritivos das mulheres, mediante reflexões que evidenciem as diferenças entre elas, consoante os grupos aos quais pertençam: as classes sociais, étnicas dentre outras categorias. ${ }^{5} \mathrm{O}$ que desvelei foram os "estilos" voluntários com concepções, comportamentos $e$ vestuário consoantes os grupos formados por mulheres nos diferentes $e$ variados núcleos de atuação voluntária, cada qual pertencendo $e$ participando do estilo da época de guerra - com mulheres contributivas, participativas e integradas ao conflito mundial $e$ as suas causas. ${ }^{6}$

\footnotetext{
4 As reflexões acerca da ideologia do patriotismo de guerra e os elementos que a compuseram foram feitas com base no estudo de Cytrynowicz (2000).

5 O campo de estudos e de debate sobre o gênero não cessa de crescer. As reflexões sintetizam o debate estabelecido entre Scott e Tilly retomado por Varikas (1994).

6 A expressão "estilo" (ou "estilos") aparece no texto com sentidos diversos: tanto para caracterizar o uso de roupas determinadas, quanto de atitudes,
} 
Ivana Guilherme Simili

\section{Mulheres cuidadosas e zelosas: a transformação pela educação}

Os cursos preparatórios para capacitar $e$ habilitar as mulheres para sua atuação na instituição, os serviços e atividades que foram estabelecidos e que visavam o envolvimento $e$ a participação feminina na composição de estilos e perfis criados para as voluntárias constituíram-se em estratégias e intervenções pedagógicas, revelando ser a Legião Brasileira de Assistência, nos anos da guerra, uma poderosa aliada na educação dirigida ao público feminino, retomando pontos $e$ aspectos presentes nos projetos pedagógicos para a modelagem de mulheres participativas, contributivas no conflito mundial.

Em 1937, o projeto pedagógico equivalente ao ensino médio e secundário implementado por Capanema na educação das mulheres - jovens entre 12 e 18 anos - havia coroado algumas concepções em voga com relação ao tipo de formação a lhes ser dada com a inclusão da "economia doméstica", de aulas de higiene, de alimentos, de vestuário, da habitação, com aulas de enfermagem para que aprendessem a cuidar dos doentes, aulas de culinária voltadas para o preparo de alimentos, a ornamentação e regras de etiqueta, aulas de sociologia educacional voltadas para a orientação de questões relacionadas à família, à Igreja e aos problemas sociais como o pauperismo (Schwartzman, Bomeny, Costa, 2000:126).

comportamentos. O suporte teórico para essa junção encontra-se na reflexão de Gilberto Freyre (1987:17), que parte do princípio de que, na língua portuguesa e na inglesa (modos e modas e moda e fashion), por vezes se confundem, permitindo que se considere "modas" em sentido mais abrangente. Dos sentidos para a moda esmiuçados pelo autor, o emprego no texto tem a ver com o "uso, hábito ou estilo geralmente aceito, variável no tempo e resultante das influências do meio" e está articulado com o de modo, no sentido de indicar "maneira, feição ou forma particular (...) educação (...); jeito, habilidade". Portanto, com o conceito de estilo ou estilos refiro-me à produção de moda sob a forma de vestuário e de comportamentos, atitudes que foram criados pelas práticas pedagógicas da Legião Brasileira para a produção de voluntárias, com determinados modos de ser, comportar-se e vestir-se. 
Educação e produção de moda na segunda guerra mundial

Os cursos para a formação das voluntárias, criados pela Legião Brasileira de Assistência entre setembro e dezembro de 1942, nos primórdios da entrada do país no conflito mundial e da organização da instituição, indicam a transformação dos conteúdos da educação formal em "especialidades" para a formação e composição de estilos voluntários, fazendo com que elas prosseguissem no aprendizado escolar, porque o público que passou a freqüentá-los era composto por jovens com idade entre 18 e 21 anos e pertencente aos segmentos médios e da elite da população feminina carioca. ${ }^{7}$

Os conhecimentos sobre higiene relacionados aos alimentos, aspecto nutricional $e$ formas de preparo deram origem ao curso para a formação das voluntárias da alimentação. Criado em setembro de 1942, com duração de um mês, a instituição almejava habilitar as mulheres

[...] para o exercício de uma importante missão de cunho social em época de guerra, qual seja a de ministrar às famílias dos cidadãos convocados para a vida militar conhecimentos úteis e objetivos sobre nutrição, orientando as donas de casa acerca do preparo de alimentos saudáveis $e$, ao mesmo tempo, acessíveis às bolsas das classes populares (Jornal Correio da Manhã, 25/09/1942:07).

\footnotetext{
7 O levantamento dos cursos da Legião Brasileira de Assistência teve suporte nas notícias veiculadas no Jornal Correio da Manhã, visto que os materiais com informações pedagógicas (currículo, professores envolvidos), se perderam com o tempo. No acervo da Comissão Consultiva de Referência e Estudos de Assistência Social (CREAS), que existia no Rio de Janeiro em 2002 e guardava os documentos da instituição, o que havia restado do período de guerra era um acervo fotográfico, alguns exemplares de boletins e relatórios institucionais. A inexistência de documentos sobre os cursos é indicativa de como as fontes para o estudo das mulheres vêm sendo tratada pelo poder público. Para suprir a carência de documentos, busquei extrair das notícias divulgadas no Correio da Manhã as informações sobre a periodização e temporalidade dos cursos, bem como as propostas pedagógicas que o nortearam, realizadas sob a forma de propaganda com o intuito de divulgar os atos e feitos da LBA.
} 
As voluntárias da alimentação - com seus conhecimentos sobre alimentos e nutrição a serem transmitidos às donas-de-casa - passam a integrar um dos estilos voluntários. O conteúdo das aulas de enfermagem do ensino secundário forneceu as bases para a preparação de outro grupo de voluntárias - as samaritanas socorristas (ou apenas socorristas) - em um curso que tinha duração de três meses. Elas aprenderam noções de primeirossocorros e foram habilitadas a prestar serviços de atendimento médico-hospitalar, inclusive para integrar a Força Expedicionária Brasileira, visto que um dos diplomas que permitiu sua inserção no Curso de Emergência do Exército foi o de samaritanas da LBA. $\mathrm{O}$ curso tinha o objetivo de organizar o pessoal de enfermagem para servir no front, com a partida do primeiro batalhão de soldados em junho de 1944. Portanto, o contato com os doentes e a experiência de cuidar deles especializam as mulheres, abrindolhes as portas para a participação feminina na guerra ${ }^{8}$.

Conhecimentos sobre tópicos da sociologia presentes na educação formal para mulheres também serão retomados, proporcionando os ensinamentos necessários à preparação das visitadoras sociais para agir nas questões sociais geradas pelo conflito mundial, transformando, assim, os conhecimentos em matéria útil e passível de ser aplicada na prática, na realidade da guerra.

As assistentes sociais, por sua vez, auxiliarão o trabalho de visitação, pois é este um dos pontos fundamentais da obra da Legião - visitar as famílias, saber de suas necessidades, para prever e prover [afirmava a notícia publicada pelo Jornal Correio da Manhã, 04/09/1942:07].

\footnotetext{
${ }^{8}$ Conforme o Edital do Exército, estas foram as exigências para que uma mulher fizesse o curso: ser brasileira, solteira ou viúva, sem filhos e "possuir diploma de enfermeira ou certificado de curso de samaritana expedidos por escola de reconhecida idoneidade ou ser enfermeira de profissão, portadora de atestado fornecido pelo estabelecimento em que serve" (Silva, 2000:112).
} 
Educação e produção de moda na segunda guerra mundial

Desenha-se, assim, um plano de ação e um comportamento feminino para as mulheres transformadas em visitadoras sociais pelo curso de emergência fornecido pelo Instituto Social, durante dois meses: enfrentar com seus conhecimentos os problemas sociais gerados pelo conflito mundial e que diziam respeito às famílias dos soldados, entenda-se, as mulheres - mães e esposas que, com a saída dos homens do núcleo familiar, tinham de aprender a lidar com questões relacionadas à sobrevivência, à educação dos filhos. Eis o núcleo de atuação das visitadoras sociais e um estilo feminino fabricado na época: zelar pelas mulheres dos soldados, "prevendo e provendo necessidades".

A concepção presente nos projetos e práticas pedagógicas dos anos 30 e 40 de que o ensino devia visar à formação das mulheres para o desempenho das funções de educadoras dos filhos da nação, de formadoras dos futuros cidadãos, dos homens da nação (Lopes, 1991), também foi levada para os espaços institucionais, produzindo as educadoras sociais (ou populares), que eram mulheres dedicadas aos cuidados da infância. O princípio que orientou a preparação dessas mulheres pela Legião Brasileira de Assistência foi o da transmissão de "conhecimentos necessários ao desempenho da nobre missão" para o cuidado de crianças em idade pré-escolar (Jornal Correio da Manhã, 13/10/1942:09).

Se as visitadoras sociais foram preparadas para ajudar na solução dos problemas sociais, as educadoras sociais, por sua vez, auxiliaram as esposas dos soldados na educação dos filhos nas creches.

Se alguns cursos tinham relação direta com as atribuições designadas como apropriadas ao feminino ${ }^{9}$, um deles, o de

9 Com relação aos cursos analisados até aqui, existe um aspecto que merece ser mencionado: os convênios celebrados com entidades. Eles foram uma característica da Legião Brasileira de Assistência. Os cursos de Socorristas ou Samaritanas Socorristas foram ministrados pela Cruz Vermelha Brasileira e Escola Ana Nery; os cursos de alimentação, pelo SAPS - Serviço de Alimentação da Previdência Social; formação das visitadoras sociais ocorreu por meio do 
formação para as voluntárias da defesa passiva antiaérea, criaria novas concepções para o lar/família nos anos de guerra.

A preparação de voluntárias da defesa passiva antiaérea estava relacionada aos problemas concernentes à segurança pública durante a participação brasileira no conflito mundial. Em fevereiro de 1942, com os primeiros ataques dos países do Eixo à costa brasileira, acentuaram-se as preocupações governamentais com a questão da defesa interna do país, e medidas de proteção à população foram adotadas. Pelo Decreto-Lei 4.098, de 06 de fevereiro de 1942, o Serviço de Defesa Passiva Antiaérea foi criado como atribuição do Ministério da Aeronáutica. Em agosto de 1942, quando o país ingressou na guerra, um novo decreto transferiu para o Ministério da Justiça e Negócios Interiores a responsabilidade pela organização do Serviço de Defesa Passiva Antiaérea no território nacional, em substituição ao Ministério da Aeronáutica. ${ }^{10}$

A constituição de um corpo feminino de voluntárias da Defesa Passiva surgiu no Brasil por intermédio da Legião Brasileira de Assistência que ofereceu, entre setembro e dezembro de 1942, o primeiro curso direcionado às mulheres. Antes disso, a Defesa Passiva era um serviço que tinha como público-alvo "todos os brasileiros maiores de 16 anos", portanto, os homens. ${ }^{11}$

Instituto Social; os cursos de educadoras sociais ou populares eram realizados na Pró-Mater, Instituto de Puericultura, Casa da Criança, Obra do Berço.

${ }^{10}$ Sobre as práticas de mobilização da população adotadas por Vargas, particularmente o Serviço de Defesa Passiva Antiaérea no Brasil, ver Cytrynowicz (2000:104).

${ }^{11}$ Segundo Cytrynowicz (2000:104), o Decreto-Lei de 06 de fevereiro de 1942 previa a mobilização de todos os brasileiros e estrangeiros maiores de 16 anos por um período de, no máximo, dez dias úteis do ano para as tarefas de proteção contra gases, remoção de pessoas intoxicadas, serviços de enfermagem, de vigilância do ar; de prevenção e de extinção de incêndios, de limpeza pública, de desinfecção, de policiamento e de fiscalização na execução das ordens. Previa, ainda, a utilização desse pessoal na construção de trincheiras e de abrigos de emergência. Para a execução dessas tarefas era necessária a obediência no recebimento das instruções sobre o serviço e o uso de máscaras, o conhecimento 
Educação e produção de moda na segunda guerra mundial

Observam-se, na inclusão do curso no rol da LBA, as influências do modelo inglês de defesa passiva, o qual preconizava a transferência de inúmeras tarefas da defesa interna ao corpo feminino auxiliar, tais como: orientar a população quanto aos procedimentos em caso de bombardeio, ajudar no socorro de feridos, informar sobre uso de máscaras, a neutralização dos efeitos de gases etc. Como uma organização paramilitar, o chefe era o coronel do exército, Orozimbo Martins Pereira, diretor do Serviço de Defesa Passiva. Seus instrutores foram civis e militares, sendo o diretor de ensino o Capitão Hugo de Matos Moura.

Os propósitos do curso eram formar voluntárias aptas a atuarem no "preparo das populações civis, além da guarda dos bens materiais, culturais e artísticos do país" (Jornal Correio da Manhã, 27/09/1942:01) e organizar os conhecimentos e os ensinamentos transmitidos às mulheres.

Ao contrário dos outros cursos que não deixaram registros sobre os formatos dos projetos pedagógicos, o curso de formação de voluntárias da Defesa Passiva Antiaérea legou documentos importantes que constam no Arquivo Capanema, no CPDOC. Por intermédio dessa documentação é possível conhecer alguns dos aspectos contemplados na formação das voluntárias. Previa-se a transmissão de conhecimentos sobre artefatos e problemas relacionados a armas e bombardeios para a ação de neutralização dos efeitos sobre a cidade e a população; previa também a preparação física, com caminhadas e exercícios que as transformassem em mulheres aptas para o desempenho de suas funções em situação de emergência e técnicas acerca de como atuar nos primeiros-socorros. Preconizava também que somente depois de diplomadas as voluntárias receberiam a "insígnia". Uma avaliação das aptidões as encaminharia para os locais onde prestariam os serviços de defesa pública (Arquivo Gustavo

da defesa individual, o recolhimento ao abrigo e a obediência na interdição do ir $e$ vir, a sujeição às ordens prescritas para a dispersão, o atendimento ao alarme, o apagamento das luzes e o atendimento à proibição de acionar automóveis. 
Capanema CPDOC-FGV-CaixaGC.A2.09.10.A). Portanto, os conhecimentos, condicionamentos físicos e psicológicos disciplinam ações, condutas e comportamentos.

Desse modo, as voluntárias da Defesa Passiva foram mulheres preparadas para o enfrentamento relativo à segurança da população e dos bens materiais: edificações, monumentos que podiam ser abatidos e/ou afetados em caso de bombardeios ao país, particularmente, nas grandes capitais como era o caso do Rio de Janeiro. A preparação física dava condições para os tipos de atuação previstos no curso.

Não há como identificar na formação das "defensoras da Pátria" o coroamento de algumas concepções sobre o papel da mulher e da educação feminina em voga nos anos 40, presentes no Estatuto da Família, elaborado por Vargas em 1941, cujo idealizador foi o Ministro da Educação e Saúde, Gustavo Capanema. Nesse estatuto, encontravam-se as representações de família, de infância, de homem, de mulher e de educação preconizadas pelo poder e que circularam pelo corpo social. Em relação à educação da mulher, o estatuto reforçava ainda mais uma tendência já antiga no Brasil, de que deveria tornar as mulheres mais "afeiçoadas ao casamento, desejosas da maternidade, competentes na criação dos filhos e capazes da administração da casa" (Schwartzman; Bomeny; Costa, 2000:126139).

Cuidar dos bens da nação - pessoas e edificações - era um aprendizado tanto para o cuidado $e$ administração de uma casa $e$ suas coisas como da habitação da grande casa - a pátria/família.

Além da transformação do conteúdo escolar e médio em "especialidades" e da apropriação de conceitos sobre a educação feminina que orientavam as intervenções nas escolas, observa-se uma outra estratégia pedagógica para o envolvimento feminino e a construção de perfis voluntários: o investimento na criação de serviços e atividades reforçadoras dos fundamentos da educação feminina que orientavam os projetos e as práticas de ensino. Os ensinamentos deviam pautar-se na transmissão de conhecimentos 
Educação e produção de moda na segunda guerra mundial

que tivessem como núcleo principal a educação no lar e suas tarefas. Essa face é muito presente no Serviço de Costura, na Campanha da Madrinha do Combatente e nas comunicadoras com o front por meio de programas radiofônicos.

As legionárias da costura, nome dado às voluntárias, foram mulheres que se dispuseram a doar seu tempo para a produção de roupas e bandagens distribuídas às famílias e usadas no front, principalmente para o atendimento médico-hospitalar. ${ }^{12}$

A campanha da "Madrinha do Combatente" teve por objetivo o envolvimento das mulheres na escrita de cartas para a troca de correspondências com os soldados no front. As participantes dos programas radiofônicos podem ser consideradas um desdobramento das madrinhas, porque se tratavam de mulheres que usavam os canais de rádio e a voz para mandar mensagens aos homens no campo de batalha. As madrinhas e as "comunicadoras sociais" compuseram o estilo das mulheres que se dedicaram ao envio de mensagens de apoio e incentivo para aqueles que estavam distantes da família, enfrentando os sofrimentos físicos e emocionais provocados pela participação numa guerra. Cuidar da matéria (roupas, artefatos médicos) e do espírito (as madrinhas, as comunicadoras pela voz) tornaram-se ocupações femininas, evidenciando a maneira pela qual os

\footnotetext{
${ }^{12}$ Para o serviço de costura são criados postos em vários pontos da cidade como, por exemplo, na sede da Legião Brasileira de Assistência que funcionava na Rua México, 158; nas lojas "Singer", especializada na venda de máquinas de costura, com várias lojas pela capital carioca; na Associação de Caridade São Marcelo; no Lar Proletário; no Centro do Hospital Evangélico; no Clube Caiçaras entre outros locais. A notícia veiculada na imprensa com o título "instalação de postos nas diferentes zonas da cidade" traz informações importantes acerca da natureza do trabalho realizado. Além de enaltecer o surgimento dos postos de costura, informava que para atender Ipanema e Leblon, havia sido instalado na Rua Prudente de Moraes, 550 o Posto número 4 da Cruz Vermelha Brasileira, que estaria aberto todos os dias, exceto aos sábados, a partir das 2 da tarde, com as seguintes atividades: segunda-feira - corte e preparo de costuras e bandagens; quarta-feira - costura à máquina, ponto de cruz e preparo de bandagens; sextafeira - costuras (Jornal Correio da Manhã, 27/09/1942:3).
} 
sentimentos altruístas e o sentimentalismo concebidos pelos homens como "próprios e naturais" ao feminino encontrou naquele período as condições para ensinar às mulheres que o amparo físico e emocional do masculino caminham juntos $e$ pertencem à esfera da atuação feminina.

Cuidar é uma atividade regida pelo gênero tanto no âmbito do mercado de trabalho como na vida privada [...] os papéis tradicionais de gênero em nossa sociedade implicam que os homens tenham "cuidado com" $e$ as mulheres "cuidem de" (Tronto, 1987:189).

Independentemente da forma assumida pela educação das mulheres na Legião Brasileira de Assistência - cursos, serviços e atividades -, os ensinamentos transmitidos eram os de que elas como voluntárias deviam aprender a atuar e agir no cuidado dos outros - dos soldados, das famílias, dos doentes, das crianças - $e$ dos bens materiais e simbólicos - casa, população.

É importante lembrar que "amparar os soldados e seus familiares" foi o objetivo fixado pela instituição, transformando-se em lema $e$ objeto dos cuidados das mulheres com vários desdobramentos. Não se deve esquecer também que ao fomentar a atuação feminina em atividades de cuidados dos outros soldados e família -, a instituição participava da construção de representações acerca de profissões $e$ atividades "tipicamente femininas", como professora (das educadoras sociais), enfermeira (samaritanas socorristas), nutricionista (no caso das voluntárias da alimentação), assistentes sociais (visitadoras sociais), costureiras. Finalmente, não podemos perder de vista a contribuição dada pela instituição para a construção da história da profissão de assistente social. Uma tendência na profissionalização feminina que vinha desde os anos 20 e 30 e ganhou fôlego particularmente nos anos 40 com a criação da Legião Brasileira de Assistência foi o desdobramento da figura da mãe em professora primária e em assistente social; esta última, uma profissão que se formava à 
Educação e produção de moda na segunda guerra mundial

época no bojo de uma série de atividades filantrópicas lideradas e exercidas por mulheres da classe média e da elite (Corrêa, 1997:8687). Tal como ocorria com a professora primária, a profissionalização de assistente social também foi estimulada pelos homens porque o seu objeto de atenção e de cuidado é o zelo pelos outros.

No entanto, embora a inserção e a participação das mulheres na instituição viabilizassem o acesso a conhecimentos "profissionalizantes", em nenhum momento deixou-se de reforçar que o papel e a função da mulher estavam voltados para o lar. Em 1944, Jorge de Medeiros publicou na Revista Cultura Política - um dos principais veículos do pensamento político dominante - esta reflexão sobre o papel da mulher na guerra:

O sentimentalismo próprio do coração feminino tem cedido lugar às contingências $e$ circunstâncias da realidade da guerra. Aos afazeres únicos e particulares do lar, precisam ser somadas as obrigações oriundas do estado de beligerância dos povos (Medeiros, 1944:145).

A presença feminina fora do lar é justificada pelas necessidades da guerra, somente assim a participação feminina é permitida, porque no âmbito da instituição, tal como na família, as mulheres deviam dedicar-se aos cuidados com os outros.

Para viabilizar os cuidados femininos na guerra, estabelecese uma divisão de tarefas consoantes os gêneros: enquanto os homens lutam, e participam da Guerra, no front, as mulheres cuidam daqueles e daquilo que foram por eles deixados no país.

As mensagens veiculadas na imprensa, desde a primeira campanha de mobilização lançada pela Legião Brasileira de Assistência para arregimentar as mulheres, revelam como os conceitos de guerra foram apropriados e usados pela instituição a fim de produzir a adesão e o envolvimento femininos aos moldes como a participação devia acontecer. "Trabalhe pela Vitória do Brasil" foi o lema criado e divulgado nos cartazes-propagandas 
publicados nos jornais. Afirmava-se também que, naquela que era uma "tremenda conflagração mundial", a mulher brasileira teria mais uma vez sua oportunidade para trabalhar

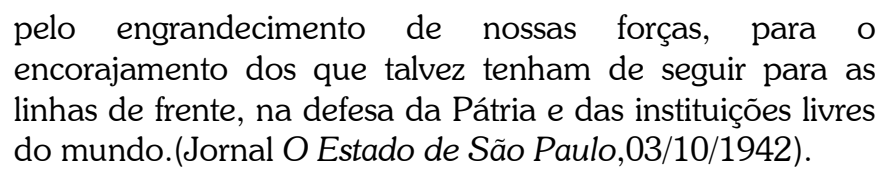

"As mulheres do Brasil", "as nobres filhas deste grande país", "as filhas da Pátria" deviam encorajar os homens a lutar, cedendo seus pais, seus filhos, seus maridos, enfim, seus afetos e amores $e$ ajudar na luta deles, participando da instituição, "amparando-os" $e$ aos "seus familiares". As mulheres deviam aderir aos esforços dos homens, cuidando e cooperando com eles.

As idéias e os conceitos patrióticos da união de esforços $e$ cooperação entre os sexos foram articulados $e$ inseridos no universo das representações das mulheres que se tornaram voluntárias, introduzindo noções sobre maneiras de pensar e de agir.

A Legião Brasileira de Assistência ensinava às mulheres, por intermédio de várias estratégias e intervenções pedagógicas, os deveres, missões e responsabilidades para com a Pátria/família, tais como cooperar, ajudar, participar em atividades e serviços de acordo com seu sexo, e que tinham como ponto central o cuidado, o zelo. Desse modo, milhares de mães são criadas no país pela Legião Brasileira de Assistência, que deve sua criação à grande-mãe Darcy Vargas. Com as voluntárias da alimentação surge a "mãe-nutriz" $e$ seus conhecimentos sobre alimentos $e$ nutrição; com as visitadoras sociais, a "mãe- zeladora" das famílias da nação e suas necessidades; com as educadoras populares, a "mãe-educadora" dos filhos do país; com as samaritanas socorristas, a "mãe-amparo na dor"; com as madrinhas dos combatentes $e$ as comunicadoras sonoras (ou sociais), a "mãeamparo espiritual" dos soldados; as legionárias da costura, a 
Educação e produção de moda na segunda guerra mundial

"mãe-zelosa do corpo"; com as voluntárias da defesa-passiva, a "mãe-guardiã dos bens - materiais e espirituais".

Portanto, cada segmento tinha um estilo, condicionando maneiras de ser, pensar, e agir, definindo formas de atuação, contribuição e de participação na guerra.

\section{A roupa e a moda: os uniformes das voluntárias}

Entre os meses de setembro e dezembro de 1942, os cursos para a formação das voluntárias, criados pela Legião Brasileira de Assistência, foram responsáveis pelo surgimento de uma variedade de tipos e estilos femininos. Cada segmento voluntário com conhecimentos, incumbências e exigências diferentes; cada grupo de mulheres com concepções de atuação $e$ de comportamentos compatíveis com a função para a qual foram preparadas; cada corpo de voluntariado com suas maneiras de trajar e apresentar-se publicamente, compondo estilos designativos das formas de cooperação, contribuição e participação feminina na guerra.

Na educação e na moda, o corpo é um dos objetos no qual se inscrevem as mudanças. O corpo é um objeto histórico com as marcas dos tempos, dos espaços e dos lugares. O corpo é, também, um objeto cultural e, enquanto tal, provisório, mutável e mutante, suscetível às inúmeras intervenções, consoante ao desenvolvimento científico e tecnológico de cada cultura, bem como de suas leis, de seus códigos morais, das representações que são criadas sobre os corpos, dos discursos que sobre eles se produzem e se reproduzem. Como um

objeto histórico e cultural, o corpo é constituído também por seu entorno, pelas roupas, pelos acessórios que o adornam, pela imagem que dele se produz, pelos sentidos que nele se incorporam, pelos vestígios que nele se exibem, pela educação de seus gestos (Goellner, 2003:28-29). 
A transformação das mulheres em voluntárias - em "mãescuidados" - pelos processos pedagógico-educacionais dos cursos que ensinaram quais comportamentos, atitudes, gestos deviam acompanhar suas atuações registrou-se nos seus corpos. Para alguns segmentos voluntários foi criado um tipo de uniforme composto por determinadas peças, com suas formas, cores $e$ estilos como no caso do guarda-pó e das toucas protetoras dos cabelos para as voluntárias da alimentação; apenas o guarda-pó para as legionárias da costura; a paramentação dos uniformes de enfermeiras para as samaritanas socorristas; os uniformes dos soldados, na versão feminina para as voluntárias da defesa passiva antiaérea.

A compreensão dos uniformes das voluntárias como vestuário de moda exige que algumas considerações sejam feitas acerca dos termos envolvidos na análise. Nesse sentido, conforme mostrou Diana Crane (2006:135-195), apoiada principalmente nas reflexões de Georg Simmel, Pierre Bourdieu, a moda tem importância social na medida em ela cria significados para o vestuário. Dois desses significados são examinados pela autora: o de instrumento de realce de si mesmo e, portanto, como meio de expandir o capital social, e o de controle social por parte de organizações públicas e privadas, reforçando, por meio das roupas, o significado de identidades econômicas ou ocupacionais. Os uniformes pertenceriam ao último tipo: como vestuário de controle social. Com base nesse pressuposto, a autora observa que a proliferação de uniformes no final do século XIX, principalmente para os trabalhadores e criados, se transformou em símbolo de identificação da classe operária e de diferenciação de outras classes sociais e que, ao serem usados pelos trabalhadores, passavam a expressar as distinções sociais que não podiam ser reveladas de forma clara pelos trajes comuns.

Instrumento de distinção social e de diferenciação entre as categorias voluntárias criadas pela LBA, eis o sentido dado aos uniformes. Por conseguinte, instrumento criado pela educação visto que se os ensinamentos transmitidos nos cursos ou 
Educação e produção de moda na segunda guerra mundial

nos serviços pretendiam inculcar determinados valores, comportamentos e o desenvolvimento de habilidades compatíveis com as funções a serem desempenhadas -, os uniformes vieram completar $e$ designar as mudanças, na medida em que as voluntárias passaram a ostentar nos seus corpos os signos das modificações empreendidas pela aprendizagem.

Para Kathia Castilho (2002:70), são os investimentos de valores (trajes e acessórios) que a pessoa passa a vestir que a configuram em um sujeito transformado, dando-lhe outra aparência capaz de, com seus novos efeitos de sentido, qualificálo, particularizá-lo, distingui-lo entre os demais pelas escolhas expostas, vestidas em seu próprio corpo. Vestidas com os uniformes, as voluntárias ostentavam sobre os corpos os signos de pertencimento à Legião Brasileira de Assistência, e os tipos e estilos das roupas as identificavam quanto aos segmentos voluntários aos quais pertenciam. Portanto, lembrando as reflexões de Crane (2006), os uniformes constituem-se em instrumento de distinção social e diferenciação das categorias voluntárias.

Os uniformes, como símbolo de transformações $e$ de traçados de pertencimento à instituição $e$ a grupos, remetem a vínculos, controles e censura. Esses sentidos aparecem destacados por Alison Lurie (1997:33), que considera o uniforme a forma extrema de roupa convencional, constituindo-se no traje totalmente determinado pelo outro, no qual o sujeito que o usa abdica do direito de agir individualmente e coloca-se, de maneira parcial ou total, sob censura. Para Jeniffer Craik (2003:06), o uso dos uniformes diria respeito ao controle do eu social, mas também do eu interno e de sua formação, ou seja, o eu interno passa a ser controlado, censurado pelo social, pelas regras impostas ao eu interno e individual, transformando-o em coletivo. Para a autora, existiriam vários sentidos no seu uso, tais como o de "compreender e obedecer às regras relativas ao exercício do uniforme, transformando as peças de roupa em manifestações comunicativas". Com os uniformes, as voluntárias comunicam a 
internalização dos comportamentos, das atitudes e dos valores que deviam orientar seu uso, porque os "uniformes são indicadores extremamente eficazes da codificação de regras apropriadas de conduta e sua internalização". Portanto, ao se mostrarem com os uniformes, as voluntárias mostram-se como mulheres "padronizadas" nas regras de conduta que deviam orientar suas atuações enquanto mães que cuidavam, que zelavam.

$\mathrm{Na}$ análise dos uniformes, Craik identifica dois tipos: uniformes quase masculinos associados à incorporação de disciplina, confiança, habilidades características para atuar na esfera pública; $e$ uniformes feminilizados que promovem treinamento físico e emocional em atributos de educação $e$ assistência.

Dentre os uniformes das voluntárias, o que foi criado para as mulheres da defesa-passiva antiaérea se tornou exemplar no sentido de possibilitar vislumbrar uma tendência da moda dos anos 40. Os uniformes dos soldados se incorporaram à educação $e$ à moda feminina, porque foi produzido um tipo de vestuário que apresenta na sua composição os tipos de "quase masculinização" e de "feminização" delineados por Craik. 
Educação e produção de moda na segunda guerra mundial

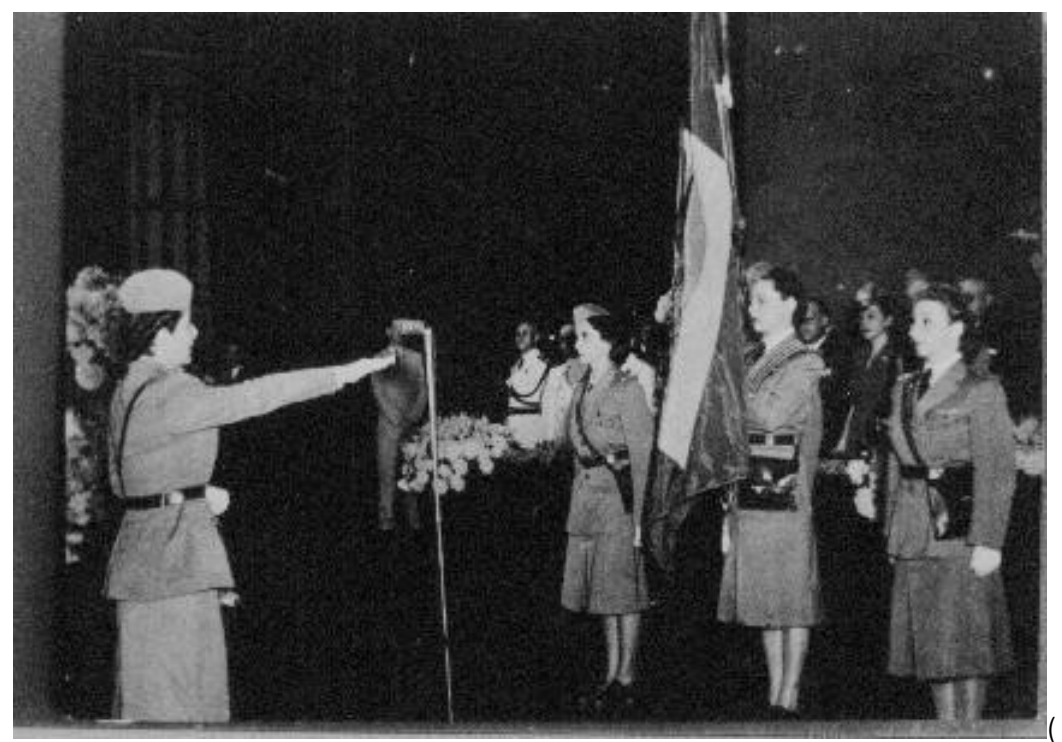

Foto Creas - Centro de Referência da Assistência Social, RJ

Este fragmento visual refere-se ao dia da formatura. O uniforme usado pelas voluntárias revela o travestir da roupa masculina para a feminina, simbolizada pela substituição de uma peça do guarda-roupa masculino - a calça - para o feminino - a saia-calça. Ao mesmo tempo, as demais peças (o quepe, o "dálmam", o cinto) permanecem como símbolos masculinos que compunham o uniforme dos soldados. São essas diferenças relacionadas aos sexos e às roupas que deixam vislumbrar os sinais de características "quase masculinas" no uniforme das voluntárias, permitindo interpretá-lo com os códigos da disciplina que orientavam a formação dos soldados da pátria - homens $e$ mulheres - e que remetem à incorporação da disciplina $e$ confiança, habilidades necessárias na proteção da população e de seus bens. 
No arquivo Capanema, no CPDOC, a documentação sobre a Defesa Passiva da Legião Brasileira de Assistência é esclarecedora:

As voluntárias pertencentes ao 'Corpo de Voluntárias', durante o Curso de Defesa Passiva A. Aé. serão sujeitas a um regimen da mais estrita disciplina, sendo eliminadas do "Corpo de Voluntárias" sumariamente quando, a critério da Direção, revelarem falta de requisitos morais, indisciplina, derrotismo, negligência no curso. ${ }^{13}$

Além da disciplina militar aplicada às mulheres a serviço da Pátria, o documento ainda aponta para a orientação dada aos instrutores de procederem a exclusão dos perfis femininos que no transcorrer do curso apresentassem atitudes morais e emocionais incompatíveis com o estilo traçado para as voluntárias da Defesa Passiva. Lembrando as palavras do Coronel Orozimbo nos dois principais atos solenes - da criação do curso e na formatura, esta última retratada na imagem fotográfica que é o suporte de nossa análise, as mulheres deviam ser "altruístas, obedientes, abnegadas e devotadas". ${ }^{14}$

É possível identificar, no curso de Defesa Passiva, as influências dos conceitos e práticas pedagógicas de militarização da educação defendidas pelas Forças Armadas desde os anos 30, e que se intensificaram a partir de 1937 com o Estado Novo. De acordo com aquela proposta pedagógica, era objetivo da educação a inculcação da disciplina, da obediência, da

${ }^{13}$ Grifo no texto original. Arquivo Gustavo Capanema CPDOC - FGV - Caixa: GC.A2.09.10. Mantive o texto conforme original e, nele, a expressão Antiaérea aparece de forma abreviada "Aé.".

${ }^{14} \mathrm{O}$ discurso do Coronel Orozimbo, publicado no Jornal Correio da Manhã (27/09/1942:1), refere-se ao serviço de defesa passiva $e$ às atividades das mulheres, afirmou: "de quase nada valerá essa modalidade de defesa se não contar com a incondicional cooperação de elementos suficientemente imbuídos do mais profundo sentimento de abnegação, de disciplina, de altruísmo, de devotamento e de valor". 
Educação e produção de moda na segunda guerra mundial

organização, do respeito à ordem $e$ às instituições, do respeito à hierarquia e o amor à pátria (Schwartzman; Bomeny; Costa, 2002:8490). São concepções que se tornaram caras e foram exploradas pela ideologia de guerra, educando os homens e mulheres, para transformá-los em "soldados da Pátria".

Há também traços da "feminização" nos uniformes das voluntárias que caracterizam o segundo tipo definido por Craik, cujo emprego pressupõe o treinamento físico e emocional para fins educacionais e assistenciais. Nas saias-calças e nas bolsas que carregavam nos cintos estavam os emblemas da feminização que se completavam com o objetivo das disciplinas do curso conhecimentos e a introjeção de regras de conduta - para educálas, de forma que as habilidades de altruísmo, obediência $e$ abnegação, consideradas "naturais", fossem alargadas para a população, na prestação de assistência à população na guerra. $\mathrm{O}$ conteúdo educativo e assistencial orientou, portanto, o treinamento físico e emocional, disciplinando - por intermédio dos uniformes - os corpos $e$ as representações e feminizando os comportamentos e condutas das mulheres na guerra.

$\mathrm{Na}$ trajetória das voluntárias da Defesa Passiva na Legião Brasileira de Assistência, registram-se a feminização da disciplina, porque que em nome da prestação de serviços à população com vistas a protegê-la dos perigos da guerra, objetivo para o qual foram preparadas, as mulheres tiveram atuação ativa em vários setores da atividade assistencial da LBA. Elas participaram de campanhas tais como a da "borracha usada", fazendo a coleta de materiais nas ruas da cidade; a das Hortas da Vitória, transmitindo conhecimentos sobre práticas de cultivo de alimentos - hortaliças, verduras e legumes - para as crianças nas escolas. Elas foram transformadas nas intermediárias entre a instituição e os soldados, fazendo a entrega dos objetos doados e produzidos pela LBA como, por exemplo, os cigarros, roupas, fósforos - aos soldados que estavam nos quartéis aguardando a partida para o front de guerra. Com essas práticas, elas puderam ter acesso a espaços interditados aos olhares e presenças femininas. Elas também 
foram as protagonistas do trabalho de patrulhamento das ruas durante os black-outs que movimentaram a vida noturna na capital carioca. Enquanto durasse o black-out, as voluntárias guardavam a cidade, pedindo aos moradores que apagassem as luzes das casas, e vistoriavam os espaços para garantir o sucesso da prática.

O percurso das voluntárias da Defesa Passiva Antiaérea indica uma ambigüidade e contradição que merecem destaque: ao mesmo tempo em que a guerra proporcionou às mulheres novas experiências - contatos com o universo masculino (espaciais e de conhecimentos dos artefatos e estratégias de guerra) e com o espaço público das ruas e seus sujeitos -, a disciplina, o devotamento, a abnegação e a obediência ditaram as regras e os códigos das condutas e do vestir. ${ }^{15}$

\section{Palavras finais...}

Transformei as voluntárias em personagens centrais para a compreensão das mudanças presentes no cenário brasileiro da educação e da moda durante os anos da participação brasileira na guerra. Por intermédio daquelas mulheres foi possível mostrar a "força dos reflexos da situação e política vigentes", que James Laver (1989) denomina a "atmosfera do momento", na educação e na moda, alterando concepções, valores, comportamentos, atitudes e criando tipologias para estilos e perfis designativos de formas de contribuição, atuação e participação feminina no conflito mundial.

$\mathrm{Na}$ criação dessas mulheres para a guerra conduzida pela Legião Brasileira de Assistência, os estilos femininos produzidos nos levam a pensar que, no período, a história da educação e da moda se relacionaram de modo a fazer com que os uniformes se transformassem em emblemas das mudanças, porque o uso deles

\footnotetext{
${ }^{15}$ Nos limites deste texto não foi possível aprofundar questões sobre o universo feminino das voluntárias da Legião Brasileira de Assistência e acerca do significado da experiência na vida delas. Sobre o assunto, ver Simili, 2008.
} 
Educação e produção de moda na segunda guerra mundial

pelas voluntárias significou a apropriação desse tipo de vestuário para fins educativos, reforçando ensinamentos, condutas, maneiras de agir e de se apresentar.

Conforme observei inicialmente, um dos aspectos salientados nos estudos da moda na Guerra é o papel desempenhado pelos uniformes dos soldados na moda feminina. A descrição feita por Dominique Veillon (2004) é exemplar no sentido de indicar a forma pela qual a Guerra ditou uma mudança no figurino $e$ nos comportamentos femininos - mediante a incorporação de peças do vestuário dos soldados no visual e no guarda-roupa como, por exemplo, o uso do chemisier cáqui, botões dourados nos casacos, os barretes, os quepes de feltros ou ainda, pela maneira que os alertas obrigaram as mulheres a proceder a uma revisão no guarda-roupa, priorizando roupas práticas e quentes como os trajes de esqui. Os novos tempos foram sinalizados pela multiplicação das mulheres fardadas, vestindo tailleur preto, camisa branca e gravata preta e pela transformação do guarda-roupa em sóbrio, marcado pelo fim dos vestidos vistosos, dos bonezinhos excêntricos, das jóias extravagantes e das unhas cor de sangue, para se restringir ao tailleur estrito, quando muito, acompanhado por um casaquinho de crepe, um chapeuzinho de feltro acompanhados por uma bolsa grande (Veillon, 2004:28).

Pode-se afirmar que os reflexos das mudanças na moda, sob a influência das roupas dos soldados, estiveram presentes no guarda-roupa das mulheres da Legião Brasileira, particularmente no vestuário das voluntárias da Defesa Passiva antiaérea, porque para sua atuação foi criada uma farda feminina. Criou-se um vestuário e uma versão feminina para os soldados da Pátria, revelando que as roupas são componentes da fabricação dos sujeitos, da sexualidade e dos gêneros, definindo comportamentos, condutas e formas de arranjos do visual, porque a disciplina, o altruísmo, os sentimentos incutidos e disseminados pela instituição passaram a guiar atuações e caminharam com as 
saias-calças, bolsas na cintura, batons na boca e unhas pintadas. Eis uma das sínteses possíveis de uma mulher na guerra.

\section{Referências bibliográficas}

Baudot, François. Moda do Século. Trad. Maria Thereza de Rezende Costa. $3^{a}$ ed. revista. São Paulo, Cosac Naify, 2002.

BraGA, João. Reflexões sobre moda. $2^{\mathrm{a}}$ ed. revisada. São Paulo, Editora Anhembi Morumbi, 2005, v.2.

CASTILHO, Khatia. Do corpo à moda: exercícios de uma prática estética. In: CASTILHO, K. e GALVÃO, Diana. A moda do corpo, o corpo da moda. São Paulo, Editora Esfera, 2002.

CORRÊA, Mariza. A cidade de menores: uma utopia dos anos 30. In: FREITAS, Marcos Cezar de. (org.) História Social da Infância no Brasil. SP, Cortez, 1997, pp.81-99.

CRAIK, Jennifer. A política cultural do uniforme. Fashion Theory, vol. 2, $\mathrm{n}^{\circ} 2$, junho de 2003, pp.5-26.

CRANE, Diana. A moda e seu papel social: classe, gênero e identidade das roupas. São Paulo, Senac, 2006. [Tradução Cristiana Coimbra]

CYTRYNOWICZ, Roney. Guerra sem Guerra - A mobilização e o cotidiano em São Paulo durante a Segunda Guerra Mundial. São Paulo, Edusp, 2000.

FeLIPE, Jane. Governando os corpos femininos. Labrys. Estudos Feministas (4), Brasília, UnB, ago./dez., 2003. Disponível em http://www.unb.br/ih/his/gefem/labrys4/textos/jane1.htm (acesso em 10/05/2004).

FREYRE, Gilberto. Modos de homem e modas de mulher. $2^{\mathrm{a}}$ ed. Rio de Janeiro, Record, 1987.

GOELLNER, Silvana V. A produção cultural do corpo. In: LOURO, Guacira L.; NECKEL, Jane Felipe; GoELLNER, Silvana V. (orgs.) Corpo, gênero e sexualidade. Um debate contemporâneo na educação. Rio Janeiro, Vozes, 2003, pp.28-40.

JODELET, Denise (org.) As representações sociais. Rio de Janeiro, Eduerj, 2001 [Trad.: Líliam Ulup]. 
Educação e produção de moda na segunda guerra mundial

LAVER, James. A roupa e a moda: uma história concisa. São Paulo, Cia. das Letras, 1989. [Trad. Glória Maria de Mello Carvalho]

LOPES, Eliane Marta. Da Sagrada missão pedagógica. Tese de doutorado, Universidade Federal de Minas Gerais, 1991.

LURIE, Alison. A linguagem das roupas. Rio de Janeiro, Rocco, 1997.

MEDEIROS, Jorge de. A mulher em face da Guerra. Cultura Política, ano IV, n 36, Rio de Janeiro, janeiro de 1944, pp.145-147.

MoutinHo, Maria Rita; VALENÇA, Máslova Teixeira. A Moda no Século XX. Rio de Janeiro, Editora Senac, 2005.

SCHWARTZMAN, Simon; Bomeny, Helena Maria Bousquet; CostA, Vanda Maria Ribeiro (Orgs.) Tempos de Capanema. São Paulo, Paz e Terra/Fundação Getúlio Vargas, 2000.

SILVA, Maristela Freitas. Resgatando a Memória: a história das enfermeiras da Força Expedicionária Brasileira na II Guerra Mundial. Dissertação de Mestrado, UERJ, Rio de Janeiro, 2000.

SIMILI, Ivana Guilherme. Mulher e política: a trajetória da primeira-dama Darcy Vargas (1930-1945). São Paulo, Edunesp, 2008.

SOARES, Carmem Lúcia. Pedagogias do Corpo. Labrys. Estudos Feministas (4), Brasilia, UnB, ago./dez. 2003. Disponível em http://www.unb.br/ih/his/gefem/labrys4/textos/car1.htm (acesso em 10/05/2004).

SouZA, Gilda de Mello. O espírito das roupas: a moda no século XIX. São Paulo, Cia. das Letras, 1987.

TRONTO, Joan C. Mulheres e cuidados: o que as feministas podem aprender sobre a moralidade a partir disso? In: JAGGAR, Alison M; BORDO, Susan. (orgs.) Gênero, corpo, conhecimento. Rio de Janeiro, Rosa dos Tempos, 1997 [Trad.: Brita Lemos de Freitas].

VARIKAS, Eleni. Gênero, experiência e subjetividade: a propósito do desacordo Tilly - Scott. Cadernos Pagu (3), Campinas-SP, Núcleo de Estudos de Gênero/Unicamp, 1994, pp.63-84.

VEILLON, Dominique. Moda \& Guerra: um retrato da França ocupada. Rio de Janeiro, Zahar Ed., 2004. [Tradução e glossário de André Telles]. 
Ivana Guilherme Simili

\section{Outras fontes}

Arquivo Capanema, Centro de Documentação de História Contemporânea do Brasil-CPDOC/FGV. Rio de Janeiro.

Arquivo Creas - Centro de Referência da Previdência Social. Rio de Janeiro (2002)

Jornal Correio da Manhã, 1942-1945.

Jornal O Estado de São Paulo, 1942-1945. 